\title{
Blood platelet activity in men with vasculogenic erectile dysfunction
}

\author{
Zeki Bayraktar, Selami Albayrak \\ Istanbul Medipol University, School of Medicine, Department of Urology, Istanbul, Turkey.
}

\begin{abstract}
Summary Objective: The aim of this study was to investigate the platelet activity in patients with vasculogenic erectile dysfunction (ED). Materials and methods: The total blood count, including hemoglobin $(\mathrm{Hgb})$, white blood cell (WBC), red blood cell $(R B C)$, platelet (PLT) and mean platelet volume (MPV) parameters were measured in the patient $(n=70)$ and control groups $(n=50)$.

Results: The average age was $48.1 \pm 11.7$ and $47.6 \pm 12.3$ in the patient and control groups $(p=0.8217)$, respectively. MPV was higher in the patient group and there was a statistically significant difference between two groups (11.27 \pm 0.56 and $9.8 \pm 0.91, p<0.0001)$. PLT counts were lower in the patient group but there was not a statistically significant difference $(196.23 \pm 37.01$ and $209.07 \pm 36.71, p=0.0626)$. In terms of haemoglobin, WBC and RBC values, there was no difference in the patient and control groups. Conclusions: Finding high MPV, which reflects the platelet activity, in the patient group shows that platelets also have a role in the VED etiopathogenesis. In the case of the confirmation of this result with additional studies, the efficiency of anti-platelet therapy in the vasculogenic ED should also be researched.
\end{abstract}

KEY WORDS: Erectile dysfunction; Platelet; Mean platelet volume.

Submitted 18 August 2017; Accepted 14 January 2017

\section{INTRODUCTION}

Erectile dysfunction (ED) is defined as the inability to attain or maintain the penile erection required for sufficient sexual performance for at least 6 months $(1,2)$.

ED is a multifactorial disease in the pathophysiology of which vascular, neurogenic, hormonal, psychogenic, cavernosal, iatrogenic, and anatomic causes play a role (3). ED may affect physical and psychosocial health and may have a significant impact on the quality of life of sufferers and their partners. Additionaly, ED can be an early manifestation of coronary artery and peripheral vascular disease (2).

In recent years, there have been some studies which report that mean platelet volume (MPV) increases in patients with vasculogenic ED (4-9). MPV is a marker of platelet size that is easily measured by automated blood counters and routinely available at a relatively low cost and reflects indirectly platelet activity. Increased production of large platelets could conribute to the pathogenesis of atherotrombosis, because large platelets are metabolically and enzymatically more active than small platelets and produce more thromboxane, known as the most potent vasoconstrictor agent. Therefore increased platelet activity play an important role in the atherosclerosis formation through mechanisms such as thrombocyte gathering, tromboxan synthesis, and expression of adhesion molecules (10-13). Increased platelet activity probably plays a role in the etiopathogenesis of vasculogenic ED with such atherothrombotic process.

The relationship between vasculogenic ED and platelet activity has been investigated in some studies (4-9). But these studies contain some conflicting results. For example, while Çifţ̧i et al. (8) stated that both platelet count (PLT) and mean platelet volume (MPV) increased in vasculogenic ED, Aldemir et al. (9) reported that platelet count was normal. In this study, it was aimed to investigate some hematological parameters such as hemoglobin (Hgb), white blood cell (WBC), red blood cell (RBC), PLT and MPV in patients with vasculogenic ED.

\section{Materials AND Methods}

The study protocol was approved by the Institutional Ethics Committee of the School of Medicine, Istanbul Medipol University, Turkey. All of the individuals gave their informed consent. 70 patients in total who came to the Urology polyclinic between May 2015 and June 2016 with the ED complaint and were diagnosed with vasculogenic ED (arterial insufficiency) were included in this study. All the patients in this group were subjected to the detailed history (anamnesis), physical examination, erectile function examination, laboratory evaluations and penile colour Doppler ultrasonography (pDUS). The ED level was questioned by International Index of Erectile Function (IIEF) which had 6 questions consisting of the $1-5$ and $15^{\text {th }}$ questions of the IIEF questionnaire $(14,15)$. According to this, those whose IIEF-ED score was $<26$ were regarded to have ED. The patients were grouped according to their erectile function area scores (Q1-5 and Q15) as mild ED (17-25), moderate ED (1116) and severe ED (6-10).

Penile color Doppler evaluation was conducted on the basis of the criteria proposed by La Vignera et al. (16). The patients were classified according to the peak systolic velocity (PSV) value obtained. According to these, PSV $\geq 35 \mathrm{~cm} / \mathrm{s}$ values were assumed as normal (no arterial insufficiency). PSV $<25 \mathrm{~cm} / \mathrm{s}$, between 25 and 29 $\mathrm{cm} / \mathrm{s}$, and between $30-34 \mathrm{~cm} / \mathrm{s}$ values were consdered as severe, moderate, and mild arterial insufficiency, respectively. All patients with PSV values $<35 \mathrm{~cm} / \mathrm{s}$ were con- 
sidered to have vasculogenic ED and were included in the study. By contrast, patients with ED, the vasculogenic ED diagnosis of which was not confirmed with USG (with peak systolic velocity $\geq 35 \mathrm{~cm} / \mathrm{s}$ ), were excluded from this study, even if their IIEF-ED score was $<26$. Additionally patients who used anti-platelet and/or anticoagulant medication, patients with neurogenic or endocrinological ED, history of pelvic surgery and pelvic trauma, prostatectomy, history of other vascular risk factors for ED such as diabetes, smoking, or hypertension, patients recently diagnosed with coronary artery disease (CAD) or hematological disorder, active infectious disease, malignancy, immunological disease, or renal or hepatic failure were excluded from this study.

The control group consisted of 50 volunteering men who came to the Urology polyclinic during the same period with the complaints different from ED such as hydrocele, varicocele, inguinal hernia, and epididymis cyst, which were sexually active, married and whose ED domain score was $\geq 26$. Those who did not apply with the ED complaint but had an IIEF-ED score $<26$ and/or had a kind of disease that may affect Hemogram parameters were not included in the control group. The patients in the control group were also subjected to the detailed sexual anamnesis, physical examination, IIEF-ED examination and laboratory evaluations as in the patient group. However, penile Doppler ultrasonography was not performed in the control group.

The total blood count, including hemoglobin ( $\mathrm{Hgb}$ ), white blood cell (WBC), red blood cell (RBC), platelet (PLT), and mean platelet volume (MPV) parameters were measured in the patient and control groups. All parameters were measured by using commercially available assay kits (Sysmex Europe GmbH, Norderstedt, Germany) with an autoanalyzer (Sysmex XT 200i, Hamburg, Germany). Blood samples were drawn from the antecubital vein and analyzed immediately (without freezing) after an overnight fasting period. The blood samples were collected in tubes containing dipotassium ethylenediaminetetraacetic acid. All the measurements were performed immediately after venipuncture to prevent in vitro platelet activation (within $1 \mathrm{~h}$ of sampling).

Statistical analyses were performed with MedCalc statistical software (Version16.4.3, MedCalc Software bvba, Ostend, Belgium). Student t-test was used for comparison of two groups (vasculogenic ED and control). $\mathrm{P}<0.05$ was used as a threshold for statistical significance. Data were presented as mean \pm standard deviation.

\section{RESULTS}

The findings are shown in Table 1 and Table 2. The average age in the patient group was $48.1 \pm 11.7$ (range 2969), the average age in the control group was $47.6 \pm 12.3$ (range 18-68) $(\mathrm{p}=0.8217)$. The IIEF scores were $13.2 \pm$ 0.5 and $27.3 \pm 1.7$ in the patient and control groups, respectively, and there was a significant difference between two groups $(p<0.0001)$. Total platelet count was lower in the patient group than the control group $(196.23 \pm 37.01$ and $209.07 \pm 36.71$, respectively) but there was not a statistically significant difference ( $p .=0.0626$ ). The MPV values were higher in the patient
Table 1.

Patients' characteristics in vasculogenic ED $(n=70)$.

\begin{tabular}{|l|c}
\hline Age & 29-69 (48.1 \pm 11.7) \\
\hline PSV, $n(\%)$ & $\begin{array}{c}\text { Severe }(<25 \mathrm{~cm} / \mathrm{s}), 23(32.8 \%) \\
\text { Moderate }(25-29 \mathrm{~cm} / \mathrm{s}), 26(37.1 \%) \\
\text { Mil }(30-34 \mathrm{~cm} / \mathrm{s}), 21(30 \%)\end{array}$ \\
\hline IIEF-ED & $13.2 \pm 0.5$ \\
\hline ED severity, $n$ (\%) & $\begin{array}{c}\text { Severe (IIEF 17-25), } 27(38.5 \%) \\
\text { Moderat (IIEF 11-16), 27 (38.5\%) } \\
\text { Mild (IIEF 6-10), 16 (22.8\%) }\end{array}$ \\
\hline WBC & $8.07 \pm 2.77$ \\
\hline RBC & $5.16 \pm 0.04$ \\
\hline Hgb & $14.89 \pm 0.86$ \\
\hline PLT & $196.23 \pm 37.01$ \\
\hline MPV & $11.27 \pm 0.56$ \\
\hline ED, erectile dysfunction; IIEF, international Index of erectile function; \\
PSV, peak systolic velocity.
\end{tabular}

\section{Table 2.}

Study parameters and results in vasculogenic ED and control group (t test, $p<0.05$, statistically significant).

\begin{tabular}{|c|c|c|c|c|}
\hline & $\begin{array}{c}\text { Vasculogenic ED } \\
\left(\text { no }^{2}=70\right)\end{array}$ & $\begin{array}{l}\text { Control } \\
(n=50)\end{array}$ & $P$ values & $\begin{array}{l}\text { Stastical } \\
\text { result }\end{array}$ \\
\hline Age & $48.1 \pm 11.7$ & $47.6 \pm 12.3$ & $p=0.8217$ & NS \\
\hline$\overline{\mathrm{IIEF}}$ & $13.2 \pm 0.5$ & $27.3 \pm 1.7$ & $p<0.0001$ & $\mathrm{~S}$ \\
\hline$\overline{\text { WBC }}$ & $8.07 \pm 2.77$ & $7.67 \pm 0.21$ & $p=0.3109$ & NS \\
\hline$\overline{\mathrm{RBC}}$ & $5.16 \pm 0.04$ & $5.23 \pm 0.53$ & $p=0.5510$ & NS \\
\hline Hgb & $14.89 \pm 0.86$ & $14.98 \pm 0.98$ & $p=0.5950$ & NS \\
\hline$\overline{\mathrm{PLT}}$ & $196.23 \pm 37.01$ & $209.07 \pm 36.71$ & $p=0.0626$ & NS \\
\hline MPV & $11.27 \pm 0.56$ & $9.8 \pm 0.91$ & $p<0.0001$ & $S$ \\
\hline
\end{tabular}

group than in the control group (11.27 \pm 0.56 and $9.8 \pm$ 0.91 , respectively) and there was a statistically significant difference ( $<0.0001$ ) (Figure 1). By contrast with this, there was not a significant difference between the patient and control groups in terms of WBC, RBC and Hemoglobin values.

\section{Discussion}

The findings obtained show that MPV values in the patients with vasculogenic ED were significantly increased when compared to the patients in the control group, however, any increase in the platelet count did not take place. These results are compatible with the previous similar studies in terms of MPV values (4-9)., but not in terms of platelet count.

According to Aldemir et al. (9), MPV values in the patients with vasculogenic ED increased significantly when compared to the control group but there was no change in the platelet count. By contrast, according to Çiftçi et al. (8), both MPV value and platelet count increased significantly in the patients with vasculogenic ED. In this study as well, MPV values were significantly higher in the patients with vasculogenic ED compared to the control group. This result (in terms of MPV) is compatible with other 


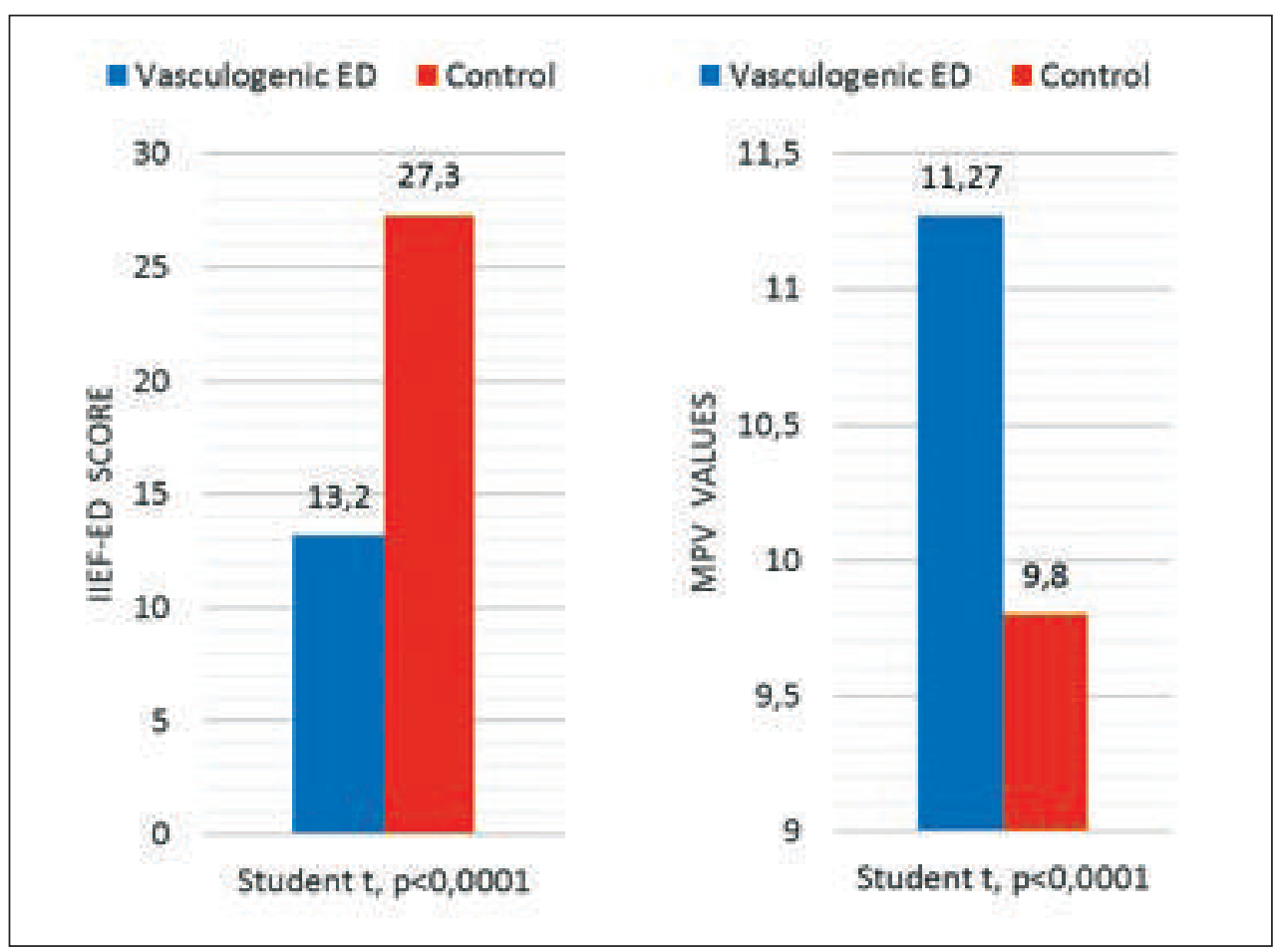

Figure 1.

Comparison of IIEF-ED and MPV values between vasculogenic $E D$ and control group. similar studies. However, platelet counts in this study were lower in the patient group. Even though this difference is not statistically significant, this result is partially compatible with the study carried out by Aldemir et al. (9) (in terms of platelet count) and contradictory with the study carried out by Çiftçi et al. (8). This contradiction may have resulted from the number of patients and/or the age difference of the patients since the average age of the patients in this study was $48.1 \pm 11.7$ years, and it was $53.70 \pm 12.39$ years in the study carried out by Çiftçi et al. (8). Nevertheless, the MPV level was found to be high in all studies including the present study.

What does the high MPV value indicate? Platelet size has been shown to reflect platelet activity. MPV is a parameter which states platelet size and indirectly proves its activity. Large platelets are metabolically and enzymatically more active than small platelets and produce more thromboxane. They show greater aggregability in response to ADP and decreased inhibition of aggregation by prostacyclin in vitro. Larger platelets are denser and contain more $\alpha$-granules, which can release prothrombotic substances, including platelet factor 4, P-selectin, and platelet-derived growth factor, a chemotactic and mitogenic factor contributing to vascular neointimal proliferation. Finally, larger platelets are more often reticulated, and this is an independent predictor of poor response to dual antiplatelet therapy $(10,11)$.

There is evidence showing an association between MPV and cardiovascular disease, peripheric artery disease (PAD) and stroke $(11,16)$. Berger et al. reported that platelets play a pivotal role in the pathogenesis of atherosclerosis and PAD. MPV, a measure of platelet size available in every blood count, is increasingly recognized as an important marker of platelet activity. Large platelet size is an independent predictor of increased risk for peripheral artery disease (17). Increased production of large platelets can contribute to the pathogenesis of atherothrombosis (18). Additionally, platelet aggregation plays an important role in the pathogenesis of acute myocardial infarction. MPV, an indicator of platelet activation, has been reported to be higher in patients with coronary artery disease compared to healthy individuals, and as a possible independent risk factor for myocardial infarction (19).

MPV can be examined in patient with erectile dysfunction because large platelets may be an indicator of the peripheral artery disease and vascular ED. Because MPV is a marker of platelet size that is easily measured by automated blood counters and routinely available at a relatively low cost (4-9, 17-19).

\section{Conclusions}

Consequently, MPV values which demonstrate the Thrombocyte activity were found to be high in the patients with vasculogenic ED. However, these data found in the limited number of patient groups with ED should be confirmed with additional studies.

Furthermore, the efficiency of the anti-platelet therapy to be performed individually or combined in the patients with vasculogenic ED who have high MPV values can also be investigated.

\section{REFERENCES}

1. Feldman HA, Goldstein I, Hatzichristou DG, et al. Impotence and its medical and psychosocial correlates: results of the Massachusetts Male Aging Study. J Urol. 1994; 151:54-61.

2. Hatzimouratidis K, Amar E, Eardley, et al. European Association 
of Urology. Guidelines on male sexual dysfunction: erectile dysfunction and premature ejaculation. Eur Urol. 2010; 57:804-14.

3. Chew KK, Bremner A, Stuckey B, et al. Is the relationship between cigarette smoking and male erectile dysfunction independent of cardiovascular disease? Findings from a populationbased cross-sectional study. J Sex Med. 2009; 6:222-31.

4. Sönmez MG, Göger YE, Sönmez LÖ, et al. Can eosinophil count, platelet count, and mean platelet volume be a positive predictive factor in penile arteriogenic erectile dysfunction etiopathogenesis? Am J Mens Health. 2016 Nov 28. pii: 1557988316679575 . [Epub ahead of print].

5. Otunctemur A, Bozkurt M, Besiroglu H, et al. Erectile Dysfunction Is Positively Correlated with Mean Platelet Volume and Platelet Count, but Not with Eosinophil Count in Peripheral Blood. Urol J. 2015; 12:2347-52.

6. Choi H, Kim JH, Shim JS, et al. Comparison of the efficacy and safety of 5-mg once-daily versus 5-mg alternate-day tadalafil in men with erectile dysfunction and lower urinary tract symptoms. Int J Impot Res. 2015; 27:33-7.

7. La Vignera S, Condorelli RA, Burgio G, et al. Functional characterization of platelets in patients with arterial erectile dysfunction. Andrology. 2014; 2:709-15.

8. Ciftci H, Gumus K, Yagmur I, et al. Assessment of Mean Platelet Volume in men with vasculogenic and nonvasculogenic erectile dysfunction. Int J Imp Research. 2015; 27:38-40.

9. Aldemir M, Akdemir F, Okulu E, et al. Evaluation of blood platelet count and function in patients with erectile dysfunction. Andrologia. 2016; 48:189-92.

10. Abdel-Rahman TM. Mean platelet volume and prognosis of unstable angina, World J Cardiovasc Dis. 2015: 5:32-41.
11. Chu SG, Becker RC, Berger PB, et al. Mean platelet volume as a predictor of cardiovascular risk: a systematic review and metaanalysis. J Thromb Haemost. 2010; 8:148-56.

12. Clappers N, Brouwer MA, Verheugt FWA. Antiplatelet treatment for coronary heart disease. Heart 2007; 93:258-265.

13. Dong JY, Zhang YH, Qin LQ. Erectile dysfunction and risk of cardiovascular disease: Meta-analysis of prospective cohort studies. J Am Coll Cardiol. 2011; 58, 1378-1385.

14. Rosen RC, Riley A, Wagner $G$, et al. The International Index of Erectile Function (IIEF): a multidimensional scale for the assessment of erectile dysfunction. Urology 1997; 49:822-830.

15. Bayraktar Z, Atun AI. Despite some comprehension problems the International Index of Erectile Function is a reliable questionnaire in erectile dysfunction. Urol Int. 2012; 88:170-6.

16. La Vignera S, Vicari E, Condorelli RA, et al. Arterial erectile dysfunction: reliability of penile Doppler evaluation integrated with serum concentrations of late endothelial progenitor cells and endothelial microparticles. J Androl. 2012; 33:412-9.

17. Berger JS, Eraso LH, Xie D, et al, III. Mean platelet volume and prevalence of peripheral artery disease, the National Health and Nutrition Examination Survey, 1999-2004 Atherosclerosis. 2010; 213:586-591.

18. Davi G, Patrono C. Platelet activation and atherothrombosis. N Engl J Med. 2007; 357:2482-94.

19. Endler $G$, Klimesch A, Sunder-Plassmann $H$, et al. Mean platelet volume is an independent risk factor for myocardial infarction but not for coronary artery disease. Br J Haematol. 2002; 117:399-404.

\section{Correspondence}

Zeki Bayraktar, MD, Urologist, Assoc. Prof. Dr. (Corresponding Author) zbayraktar@medipol.edu.tr

Istanbul Medipol University, School of Medicine, Department of Urology, Çamlık Mah. Piri Reis Cad. Papatya Sitesi No:48

34890, Pendik - Istanbul, Turkey

Selami Albayrak, MD, Urologist, Prof. Dr.

salbayrak@medipol.edu.tr

Istanbul Medipol University, School of Medicine, Department of Urology, Istanbul, Turkey 